\section{GREQAM}

Groupement de Recherche en Economie Quantitative d'Aix-Marseille - UMR-CNRS 6579

Ecole des Hautes études en Sciences Sociales Universités d'Aix-Marseille II et III
Document de Travail $n^{\circ} 2011-47$

\title{
Capital Utilisation and Retirement
}

\author{
Antoine Bonleu \\ Gilbert Cette \\ Guillaume Horny
}

October 2011 
06 September 2011

\title{
Capital Utilisation and Retirement
}

\author{
Antoine Bonleu*, Gilbert Cette** and Guillaume Horny***
}

\begin{abstract}
:
This empirical analysis aims at assessing the effect of the economic climate and the intensity of capital utilisation on companies' capital retirement behaviour. It is conducted using individual company data, as well as original data on the degree of utilisation of production factors. The sample includes 6,998 observations over the period 1996-2008. This database is, to our knowledge, unique for the empirical analysis of the intensity of capital utilisation on firms' capital retirement behaviour. We adjust for endogeneity biases by means of instrumental variables.

The main results obtained from the estimation of capital retirement models may be summarised as follows: i) The retirement rate decreases with the variations in cyclical pressures measured by the changes in output and the workweek of capital; this relation corresponds to a countercyclical decelerator effect on capital retirement; ii) The capital retirement rate increases with the structural intensity of capital utilisation; this effect, which corresponds to a wear and tear one, is nevertheless small compared to the decelerator one; iii) The profit rate does not have a significant impact on the retirement rate. Compared with the existing literature, here mainly Mairesse and Dormont (1985), the contribution of these results is to show, through the use of unique survey data, that the effect of the intensity of capital utilisation on capital retirement is structurally positive, via a wear and tear effect, and cyclically negative, via a decelerator effect which completes that already taken into account via the effect of changes in value added.
\end{abstract}

Key words: Capital; Capital measure; Capital retirement; Capital utilisation JEL codes: $\quad$ E22; D24; O16

* : Université de la Méditerranée (GREQAM), antoine.bonleu@ @otmail.fr.

** : Banque de France and Université de la Méditerranée (DEFI), gilbert.cette@ @anque-france.fr

*** : Banque de France, guillaume.horny@banque-france.fr.

The authors thank Fabrice Collard for his very useful remarks and suggestions. The views expressed herein are those of the authors and do not necessarily reflect the views of the Banque de France. 


\section{Introduction}

The macroeconomic literature underlines the decisive role of the capital stock in the potential output evaluation, and also in determining the position of the economy in the business cycle and the inflationary pressures. Not surprisingly, investment plays an important role in this literature which, nevertheless, ignores generally the capital retirement firm behaviour.

To our knowledge, the assessments of the fixed capital stock conducted by national statistics institutes always assume invariant distributions of the life span of fixed assets (law of obsolescence) over time for each one of the different products that make up capital (for a summary, see OECD, 2009). The retirement rate of capital measures that result from these approaches may then vary over time due to: i) changes in the product structure of the capital if the laws of obsolescence differ for each product; ii) changes in the age structure of the capital if the laws of obsolescence suppose that the retirement rate varies according to the age of equipment. Given how difficult it is to model and estimate in all its complexity companies' capital retirement behaviour, the assumption of invariant obsolescence laws by product adopted by national accountants seems prudent, especially as its divergence with economic reality probably has no significant consequence for the analysis of growth factors over relatively long periods or between periods characterized by similar cyclical pressures. However, it may have more significant consequences in short-term analyses or in the event of large cyclical shocks. For example, the sharp fall in capacity utilisation rate indicators during the current crisis was probably accompanied by acceleration in capital retirement. Assessments drawing on capital series based on the assumption of time-invariant obsolescence laws could show a bias of an uncertain scale. Thus, measures of potential GDP based on such assessments of capital could overestimate the potential GDP and therefore the output gap (in absolute terms) and, consequently, the disinflationary pressures caused by the crisis.

The aim of our study is to analyse empirically the capital retirement behaviour, using for this individual French firm data. The estimated model characterises the companies' capital retirement behaviour, and devotes a particular attention to the distinction of the specific impacts, on the retirement rate, of cyclical and structural effects.

Intuition suggests that the intensity of capital utilisation must probably have an impact on the retirement rate through two channels: i) the first, which is structural, corresponds to a simple wear and tear effect: the retirement rate increases with the intensity of capital utilisation; ii) the second, more cyclical, corresponds to the lags in the adjustment of capital to its targeted level through investment alone, which would result in an adjustment, at least in part, via capital retirement. In this second channel, the retirement rate would decrease with the rise in pressures on the utilisation of capital. The capital retirement behaviour would add its effects to the investment behaviour to adjust the capital to its targeted level. To the investment accelerator mechanism would corespond a capital retirement one. Beyond the mere structural and cyclical effects of capital utilisation, intuition also suggests that the financial situation of companies probably has an impact on their capital retirement behaviour: if a firm has problems financing its targeted investment level, it would lower its retirement rate.

To our knowledge, the only analysis of companies' capital retirement behaviour based on individual firm data is that conducted by Mairesse and Dormont (1985). This analysis is based on panels of several hundred French, German and US companies, the data used being drawn from balance sheets and profit and loss accounts. It shows that companies' capital retirement behaviour is, to a large extent, influenced by cyclical developments. Variations in value added have an adverse effect on the retirement rate, which suggests the existence of a countercyclical effect on capital retirement, while the profit rate is found to have a generally negligible effect. 
Our analysis builds on that of Mairesse and Dormont (1985), using a large sample of French firms. It is based on unique data on the degree of utilisation of production factors. More precisely, our empirical analysis is based on a database which merges two sorts of individual company data collected by the Banque de France: those from the FIBEN database and those obtained from a specific survey on the utilisation of production factors. FIBEN is a very large individual company database that draws on annual tax statements including balance sheets and profit and loss accounts. This database can be used to calculate retirement rates, changes in output and corporate profitability. The survey on the degree of utilisation of production factors has been carried out every year since 1989 by the Banque de France at plant level. Companies are questioned on the changes in the workweek of capital and their use of shift work. This information gives us an indication of the intensity of capital utilisation and its cyclical variations. The merger of these two databases results in an unbalanced sample of 35,679 observations over the period 1989-2008. Given the lag structure used for estimations, these may be carried out on 6,998 observations corresponding to 1,443 companies over the period 1996-2008. To our knowledge, this individual company database is unique for conducting an empirical analysis of the effects of the intensity of capital utilisation on companies' capital retirement behaviour. The empirical analysis of companies' capital retirement behaviour is conducted with these data and adjusted for endogeneity biases by means of instrumental variables.

The main results of the analysis may be summarized as follows: i) The retirement rate decreases with the variations in cyclical pressures measured by the changes in output and the workweek of capital; this relation corresponds to a countercyclical decelerator effect on capital retirement; ii) The capital retirement rate increases with the structural intensity of capital utilisation; this effect, which corresponds to a wear and tear one, is nevertheless small compared to the decelerator one; iii) The profit rate does not have a significant impact on the retirement rate. Compared with the existing literature, here mainly Mairesse and Dormont (1985), the contribution of these results is to show, through the use of unique survey data, that the effect of the intensity of capital utilisation on capital retirement is structurally positive, via a wear and tear effect, and cyclically negative, via a decelerator effect which completes that already taken into account via the effect of changes in value added.

These empirical results give some perspectives to the theoretical studies on growth or those based on calibrated models which often assume that the retirement rate increases with the intensity of capital utilisation (see, for example, among others, Greenwood, Hercowitz and Huffman, 1988, and Burnside and Eichenbaum, 1996). To use the same terminology as above, these studies assume usually that the structural wear and tear effects outweigh any opposite decelerator effects on capital retirement. This assumption is, however, not based on any empirical confirmation. It could have an important impact on the evaluation of short term impact of shocks (technological or others) on growth, since the capital retirement influences the investment expected rate of return (Cf. Veracierto, 2002).

The literature on capital retirement is mainly conducted at the macroeconomic level. Several papers underline the complexity of a measurement of the capital retirement at this macroeconomic level, pointing that this measurement should be linked to assumptions concerning the technological progress, incorporated or not (see among others Diewert and Wykoff, 2006, or Bitros et al., 2007), and that it could use available data concerning the capital second-hand market (for a survey, see Jorgenson, 1996). Our study is, whith Mairesse and Dormont (1985), one of the rare ones which link the business cycle to the capital retirement behaviour.

Section 2 presents the data used in the empirical analysis. Sections 3 and 4 present the results of model estimations first by taking no account of the degree of capital utilisation, then by factoring it in. Section 5 concludes. 


\section{Data}

The empirical analysis is based on a database that results from the merger of two types of individual company data collected by the Banque de France: those contained in the FIBEN database and those obtained from a specific survey on the utilisation of production factors.

FIBEN is a very large individual company database that draws on annual tax statements including balance sheets and profit and loss accounts. It covers all French companies with an annual turnover of over EUR 0.75 million or with a loan of at least EUR 0.38 million. It contains annual account data for roughly 200,000 companies. It may be used to calculate for every company and for every year the real value added $(Q)$, the stock of capital $(K)$, the volume of investment $(I)$, the retirement rate $(R R)$ and the profit rate $(P R)^{1}$ :

- The real value added $(Q)$ is calculated by dividing the nominal value added by a sectoral value added price index supplied by the national accounts. The nominal value added is the maximum of both the value added (output minus intermediate consumption) and the compensation of employees.

- The volume of capital stock $(K)$ is the sum of the volume of capital for two products: buildings and equipment. For each of these two products, the volume of capital is obtained by dividing the gross capital stock at historic cost obtained from company accounts by an investment price index supplied by national accounts, this index being lagged by the average age of capital. The average age of capital is calculated for each of these two products using the share of depreciated capital in the gross capital stock at historic cost.

- The volume of investment $(I)$ is calculated by dividing productive investment in nominal terms (investment in tangible fixed assets minus the variation in gross land stock when it is positive) by an investment price index obtained from the national accounts.

- The retirement rate $(R R)$ is obtained by dividing capital retirement in real terms $(R)$ of the year under consideration by the stock of capital at the end of the previous year $\left(R R_{t}=R_{t} / K_{t-1}\right)$. Capital retirement in real terms $(R)$ is calculated as the variation in the volume of capital minus the volume of investment $(R=\Delta K-I)$.

- The profit rate $(P R)$ is calculated by dividing the gross operating surplus by the stock of capital in nominal terms, i.e. by capital stock in real terms multiplied by an investment price index supplied by the national accounts. The gross operating surplus is the difference between value added and the compensation of employees.

The survey on the degree of utilisation of production factors has been conducted every year since 1989 by the Banque de France on 1,500 to 2,000 companies. These companies are those usually questioned in the framework of the Banque de France's monthly survey on business activity. In the survey on the degree of utilisation of production factors, companies are questioned about the changes in the workweek of capital, with respect to the previous year, and their use of shift work. These variables give us an indication of the intensity of capital utilisation. Two variables from this database are used in

\footnotetext{
1 In this study, the variables in upper or lower case indicate respectively their level or their natural (napieren) logarithm, and $\Delta$ before a variable corresponds to its change compared with the previous period.
} 
the following empirical analysis: the change in the workweek of capital from one period to the next and the proportion of years during which the firm is using shift work :

- The change in the workweek of capital $\left(\Delta c w_{i t}\right)$ is obtained by the answer to the question: "What is (in \%) the change in the workweek of capital between the reference week of year $t-1$ and that of year $t$ (no decimals)?". The explanatory note attached to the questionnaire provides a definition of the workweek of capital: it is defined as the average number of hours during which the capital is used over the reference period. It does not include maintenance time, but covers all the time during which the machine is running including the time required to prepare production.

- The proportion of years during which the firm is using shift work $\left(S W_{i}\right)$ is obtained by dividing the number of years during which the firm is using shift work by the total number of years during which the firm appears in our estimation period (1996-2008). The use of shift work is known from the answer ("yes" or "no") to the question: "Have you practice shift work during the reference week?". Figure A1-3 in Appendix 1 is an histogram of this variable, showing that it is highly concentrated around 0 and 1 , which confirms that the use of shifwork is mainly a structural choice.

The survey on the workweek of capital is conducted at the plant level, while the FIBEN data concern companies that may be composed of several plants. When several plants of a same company are covered by the survey on the degree of utilisation of production factors, the replies of the different plants are aggregated. The survey variables are then calculated at the company level by means of a sum weighted by the share of each plant in the company's total employment. The database only includes the companies for which the sum of the staff employed by the different plants is at least equal to $50 \%$ of employees contained in the FIBEN database. In total, only 64 observations of the database used here correspond to multi-plant companies.

The merger of these two databases results in an unbalanced database of 35,679 observations over the 1989-2008 period. Given the lag structure used for the estimations, the latter may be performed on 6,998 observations corresponding to 1,443 companies over the 1996 - 2008 time period. To our knowledge, this individual company database is unique for conducting an empirical analysis of the effects of the intensity of capital utilisation on capital retirement. Descriptive statistics of the variables obtained are presented in Table A1-1 of Appendix 1. Figure A1-1 presents kernel density estimates of the retirement rate. The distribution is highly concentrated around its mode and looks like a lognormal distribution, with almost half of the observations ranging between $1 \%$ and $6 \%$ (Table A1-1). The right-hand tail is longer than the left-hand tail given the lower bound of 0 . Mairesse and Dormont (1985) report similar average retirement rates, of around 3\% to 6\% in the 1970s in France.

The average retirement rates calculated for each company separately range between $0 \%$ and $41 \%$, with a standard deviation of 5\%. Slightly larger variations are observed over time for a given company. Indeed, the retirement rate shows a within standard deviation of $6 \%$. The within firm variations in the retirement rate are thus slightly larger than the between firm variations, an observation that represents a further incentive to study what lies at the root of retirement rate dynamics at the firm level.

\section{A reduced-form model of capital retirement}

The first part of our approach builds on an accelerator - profit model, in line with Eisner (1977) and Mairesse and Dormont (1985). It is reduced form model mostly used for the analysis of corporate investment (see Bond and Van Reenen, 2007, for a survey). We extend later the specification to account 
for business cycles. Finally, we focus on the permanent level of capital retirement at the firm level over the whole time period, that we model using firms' characteristics.

\subsection{The model}

We denote by $i$ the firm index and by $t$ the year index. The first relation we study is a reduced form of the accelerator - profit type. It relates the capital retirement rate with the production and profits, both current and past, so that the adjustments can occur with lags owing to rigidities. It has the following general form:

(1) $R R_{i t}=\beta_{0}+\beta_{10} \cdot \Delta q_{i t}+\beta_{11} \cdot \Delta q_{i t-1}+\beta_{12} \cdot \Delta q_{i t-2}+\beta_{20} \cdot P R_{i t}+\beta_{21} \cdot P R_{i t-1}+\beta_{22} \cdot P R_{i t-2}+$ $d_{t}+\mu_{i}+\varepsilon_{i t}$

This specification relates the capital retirement rate $R R_{i t}$ with the value added growth rate $\Delta q_{i t}$ and its values lagged up to two periods, the profit rate $P R_{i t}$ and its values lagged up to two periods, yearly indicators $d_{t}$, a fixed effect $\mu_{i}$ specific to each company and capturing the unobserved heterogeneity at the level of the firms, and lastly i.i.d gaussian error terms $\varepsilon_{i t}$. The number of lags is arbitrarily set to two, as will be discussed in Section 4.1. The model can obviously be adjusted to a different number of lagged variables. Equation (1) is formulated in rates rather than in levels, to reduce the variability resulting from the size differences among firms, and so heteroskedasticity problems.

Equation (1) captures the role of the demand, through the value added, and of the financial state of the firm, through its' profit rate. Indeed, the firm permanently adjusts to its' optimal level of active capital, knowing that insufficient capabilities can prevent it to satisfy its' demand, whereas an excess of capabilities raises maintenance and opportunity costs. Mairesse and Dormont (1985) find that output variations have a negative effect on the retirement rate. This decelerator effect of the activity level on the capital retirement rate is related to the willing to keep a substantial capital stock to face a positive demand shock. Conversely, companies use phases of slow activity to reduce the costs related to overcapabilities, and enhance their productivity in scrapping unused equipments. The intuition suggests that the capital retirement behaviour can also depend on the financial state of the firm. Indeed, the most profitable firms can more easily finance new productive capital, and thus easily scrap the less performing equipments. Conversely, the less profitable firms can hardly fund new equipments and reduce the capital retirement. We thus consider in the model a measure of the firms' profitability. Mairesse and Dormont (1985) do not find a clear effect of profitability on capital retirement.

We then extend the accelerator-profit model to account for business cycles. We first want to assess if the effect of the activity on the retirement varies along the cycle. A decelerator effect of activity can be explained by the choice to adjust capital to a demand shock, either positive or negative. We want to assess whether this effect is strengthened during the ascending or descending phase of the cycle.We allow for the possibility that both effects differ in magnitude by separating the valued added increases and decreases in the model. Subsequently, we add variables measuring the workweek of capital. Indeed, work shifts may be arranged in different ways due to their market peculiarities (daily interruption, weekly interruption, etc.). It translates in different capital workweek (hereafter labelled $\mathrm{CW}$ ), that can vary both structurally and cyclically. We focus here on cyclical variations, and thus include in the specification the variations over the last 12 months of the workweek of productive capital. Variations in capital utilisation also do not necessarily produce symmetrical effects on capital retirement, and we therefore distinguish between increases and decreases in the capital workweek :

(2) $R R_{i t}=\beta_{0}+\beta_{10 h} \cdot I_{-} \Delta q_{i t}+\beta_{10 b} \cdot D_{-} \Delta q_{i t}+\beta_{20} \cdot P R_{i t}+\beta_{30 h} \cdot I_{-} \Delta c w_{i t}+\beta_{30 b} \cdot D_{-} \Delta c w_{i t}$ $+d_{t}+\mu_{i}+\varepsilon_{i t}$ 
where $I_{-} \Delta q_{i t}$ and $D_{-} \Delta q_{i t}$ measure increases and decreases of the value added $\left(I_{-} \Delta q_{i t}\right.$ is always positive and $D_{-} \Delta q_{i t}$ negative), and $I_{-} \Delta c w_{i t}$ and $D_{-} \Delta c w_{i t}$ denote increases and decreases over the last 12 months of the workweek of productive capital. The expected signs of coefficients $\beta_{30 h}$ and $\beta_{30 b}$ is at first unknown. Indeed, variations in the workweek of capital can enable to adjust the production capacities to their desired levels in accordance to the retirement rate. A negative $\beta_{30 h}\left(\beta_{30 b}\right.$ respectively) is related to, when the capital workweek is increasing (decreasing), an increased (decreased) intensity in the use of the equipments and to a lesser (higher) retirement, that is, everything else equal, to an acceleration (a deceleration) in capital accumulation. These two mechanisms lead to an increase (decrease) in production capacities, and are complementary from this perspective. On the opposite, when $\beta_{30 h}$ or $\beta_{30 b}$ are positive, the evolutions of both the capital workweek and the stock of capital are conflicting. In this case, variations in the capital workweek allow softening the impact of the retirement on production capacities.

In a last stage, we are studying the impact of the structural workweek of capital on capital retirement. Theoretical works on growth models assume a wear and tear effect, implying that a high activity leads to a high level of retirement. To assess this point, we are investigating the variations between firms of a measure of retirement net of cyclical effects. This measure is obtained after estimation of equation (2), and consists in the estimated firm fixed effects $\hat{\mu}_{\mathrm{i}}^{2}$. They can be regressed on the average over the time period of the firm characteristics:

(3) $\hat{\mu}_{i}=\gamma_{0}+\gamma_{1} S W_{i}+\gamma_{2} I N D_{i}+\gamma_{3} S I Z_{i}+u_{i}$,

where $S W_{i}$ is the proportion of years some part of workforce of firm $i$ works in shifts. It does vary only with the number of years in which work is organized in successive shifts. Therefore, it is only related to the duration of period of tense capital workweek. Variables $I N D_{i}$ and $S I Z_{i}$ are sets of industry and size dummies. This simple specification enables us to avoid any cyclicality in the measure of the structural workweek of capital. Furthermore, it provides estimated standard-errors adjusted for any correlation of the error terms within firms.

\subsection{Selection of instrumental variables}

Numerous sources of endogeneity are likely to bias the estimators. On one side, it is very likely that capital retirement, value added, profitability are determined simultaneously. Indeed, the retirement rate and the profit rate are both normalized by the capital in the previous year, the value added can vary due to change in intermediate consumptions resulting from the retirement of obsolete capital, and the profit rate is a function of the value added. On the other side, the variable measuring changes in the capital workweek displays values concentrated on a few points. Figure A1-2, in Appendix 1, is a histogram of the changes in the capital workweek over the previous year. Most variations are concentrated around $-20 \%$, $10 \%,-5 \%, 0 \%, 5 \%, 10 \%$ and $20 \%$, whereas the variable should at the first glance be continuous. It is therefore likely there are measurement errors in the observed workweek of capital.

We choose to correct the endogeneity biases with instrumental variables, using essentially lagged values of the explanatory variables, in the spirit of Blundell and Bond (1998). Lagged variables can be used as instruments under the weak exogeneity assumption, meaning the absence of correlation between $\varepsilon_{i t}$ and the previous values of the explanatory variables. This assumption holds here if the current level of capital retirement does not depend on lags older than the ones included in the model (1) and (2).

\footnotetext{
2 A method to estimate the firm fixed effects in a linear model for panel data is provided in Wooldridge (2001, p. 273).
} 
Our set of instruments consists in the lagged values and two more variables. The first one is the industry yearly average of the changes in the workweek of capital, ${ }^{3}$ and the second one is a variable indicating limits to extensions of the capital workweek. More precisely, it is a dummy equal to one when the firm answers during the survey that it encounters obstacles to extend the workweek of capital while the demand allows for it. Estimates of fixed effects Logit models, not reported in the paper, let us think that companies just raising the workweek of capital during the preceeding years are most likely to declare themselves as restricted.

Our instruments must satisfy two conditions to be valid: They must be free of any correlation with the error terms and be reasonably correlated with the potentially endogenous variables. Internal instruments are generally used in great numbers, whereas each one is only weakly correlated with the endogenous explanatory variables. This can lead to substantial biases. Angrist and Pischke (2009, pp. 205-216) describe the problems raised by the use of weak instruments. To restrict the number of instruments and include only the ones containing most of the information on the variables, we follow a pragmatic strategy. We first estimate model (1) including as instruments the lagged values of all the explanatory variables until $t-6$. Hence, based on the first stage results, we dropped the weaker instruments. We are enabled by Sargan's statistic to test the exogeneity of the instruments, and by Cragg - Donald (1993) statistic associated to Stock and Yogo (2002) critical values, to test their correlation with the endogenous explanatory variables. We hence obtain a set of instruments for equation (1), whose properties are discussed in Section 4.1. We apply after the appropriate decomposition in increases and decreases to obtain model (2) instrumental variables, and then added the lagged values related to workweek of capital. As the lagged values of the workweek of capital are susceptible to measurement errors, we prefer to use as instruments dummies of their increases and decreases. It is indeed unlikely that such broad variations are missmeasured by the answering firm. As previously, we include lags up to $t-6$ before removing some instruments based on the first stage results. Properties of the instruments are presented in Section 4.2.

We use the LIML estimator. This choice is motivated by several reasons. First, it is far less susceptible to biases than the usual two-stage GMM estimator in presence of weak instruments and finite samples, as shown by the values tabulated in Stock and Yogo (2002) for the LIML and two-stage GMM, as well as by Hahn et al. (2004). Several other alternative estimators are less biased than the two-stage GMM estimator when the model is overidentified, as it is the case here. The LIML estimator neverthess seems superior with respect to several criteria (Flores - Lagunes, 2007). Furthermore, Stock and Yogo (2002) provides tables allowing the directly test the assumption of weak instruments with Cragg-Donald statistic. Those tables have been obtained under the assumption of i.i.d and homoscedastik errors. We are not aware of similar tables under the assumption of heteroscedastik errors, that could be used for example to validate instruments used by the CUE-GMM estimator of Hansen et al. (2006). As it seems of importance to us to reduce as far as possible potential biases, as well as being able to discuss the relevance of the instruments, we decide to use the LIML estimator. Estimates are performed using Stata and the ivreg2 (Baum et al., 2010) procedure. Firms fixed effects are eliminated using the within transformation.

\section{Results}

In a first section, we present the results of an accelerator - profit model similar to the one used by Mairesse and Dormont (1985). We then introduce variables which capture the intensity of capital utilisation, first from a cyclical viewpoint is Section 4.2, and second from a structural viewpoint in Section 4.3 .

\footnotetext{
${ }^{3}$ Sixteen industries are defined, according to the Nomenclature Economique de Synthèse of the INSEE.
} 


\subsection{The accelerator - profit model}

Table 1 shows several estimates derived from equation (1). A first set of results, denoted by $\mathrm{W}$, are obtained using the within estimator that assumes all the explanatory variables to be exogenous. We examine in particular the lags structure that are pertinent under this assumption. A second set of results, obtained using the LIML estimator, assumes that the explanatory variables are endogenous and the error terms homoscedastik. The choice of instruments used in the tables below is described in Section 3.2.

Table 1

Estimates of relation (1) with different lags and exogeneity assumptions

\begin{tabular}{|c|c|c|c|c|c|c|}
\hline Estimateur & $\mathbf{W}$ & $\mathbf{W}$ & W & $\mathbf{W}$ & LIML & LIML \\
\hline \multirow[t]{2}{*}{$\Delta \boldsymbol{q}_{i t}$} & $-3.25^{*}$ & $-3.43^{*}$ & $-2.94^{*}$ & $-3.26^{*}$ & $-4.74^{*}$ & -2.06 \\
\hline & $(-5.31)$ & $(-5.72)$ & $(-5.49)$ & $(-6.28)$ & $(-2.17)$ & $(-0.68)$ \\
\hline \multirow{2}{*}{$\Delta \boldsymbol{q}_{i t-1}$} & 0.25 & -0.22 & & & & \\
\hline & $(0.38)$ & $(-0.38)$ & & & & \\
\hline \multirow[t]{2}{*}{$\Delta \boldsymbol{q}_{i t-2}$} & 0.59 & & & & & \\
\hline & $(1.02)$ & & & & & \\
\hline \multirow[t]{2}{*}{$P R_{i t}$} & 0.14 & 0.23 & -0.18 & & -3.24 & \\
\hline & $(0.29)$ & $(0.49)$ & $(-0.43)$ & & $(-1.61)$ & \\
\hline \multirow[t]{2}{*}{$P R_{i t-1}$} & $-1.03^{*}$ & -0.76 & & -0.71 & & 0.20 \\
\hline & $(-2.09)$ & $(-1.73)$ & & $(-1.85)$ & & $(0.15)$ \\
\hline \multirow[t]{2}{*}{$P R_{i t-2}$} & 0.37 & & & & & \\
\hline & $(0.86)$ & & & & & \\
\hline Year dummies & Yes & Yes & Yes & Yes & Yes & Yes \\
\hline Firm fixed effects & Yes & Yes & Yes & Yes & Yes & Yes \\
\hline Instrumental variables & No & No & No & No & Yes & Yes \\
\hline $\begin{array}{l}\text { Critical prob. of Sargan's } \\
\text { test }\end{array}$ & - & - & - & - & 0.77 & 0.84 \\
\hline $\mathbf{N}$ & 6998 & 6998 & 6998 & 6998 & 6998 & 6998 \\
\hline
\end{tabular}

All the within estimates indicate lower value-added change coefficients for lagged values than for the current value, which is coherent with a model where the capital adjustments are slowed by rigidities. Only the coefficients of contemporary values are significant. Conversely, the profit rate is not significant, even under different lags structure. Similar results were obtained by Mairesse and Dormont (1985).

The LIML estimator here used the first set of instruments presented in Section 3.2. The validity of the instruments is tested in a variety of ways. A Sargan test concludes at the threshold of $77 \%$ to the absence of a correlation between the instruments and the error term. We test the assumption of weak instruments using Stock and Yogo (2002) procedure. The Cragg-Donald (1993) statistic is evaluated 17.78, for the model in the penultimate column, and 25.51 for the one in the last column. The critical value for the LIML estimator when there are two endogeneous variables and six excluded instruments is of 4.06 (Stock and Yogo, 2002, Table 4, p. 61). We can thus reject the assumption of weak instruments in both specifications. First stage results are show in Table A2.1 in Appendix 2.

The results obtained with the LIML estimator indicate that the coefficient of $\Delta q_{i t}$ remains significant when the endogeneity is taken into account and the current profit rate is included among the covariates. Compared to the within estimates, the LIML ones react and decrease when we use instrumental variables. 
This let us think there is here a simulataneity that must be handled. As we did with the within estimator, we test different specifications including several lags and therefore several sets of instruments. Their results indicate that the contemporary values of the explanatory variables capture most of the dynamics and that no lagged variable has any significant effect on the capital retirement rate, nor increases the model fit. The adjustment periods do not play an important role either in the results of the within estimator or in the results of the LIML one. We thus focus hereafter on a specification that only introduces explanatory variables at time $t$.

Taking all the specifications together, we observe that a growth in value-added has a negative impact on the capital retirement rate. This decelerator effect, already found by Mairesse and Dormont (1985), means that in the event of a cyclical positive demand shock, companies adjust partly their production capacity by reducing the retirements. Conversly, in the event of weak business, firms increases the retirement of useless equipments.

\subsection{The effects of cyclical variations of the capital workweek}

This Section presents the estimates of model (2). We first assess whether the decelerator effect pointed in Section 4.1 is strengthened during the ascending or descending phase of the cycle; with a specification that allows growth in value added to have asymmetrical effects on capital retirement. Then, we broaden this specification to assess how the decelerator effect reacts to variations in the capital workweek. All the results are obtained using the LIML estimator in order to correct the estimates for endogeneity problems.

Table 2

Estimates of the relation (2)

\begin{tabular}{|c|c|c|c|c|}
\hline Estimateur & LIML & LIML & LIML & LIML \\
\hline \multirow{2}{*}{$I_{-} \Delta q_{i t}$} & 5.49 & 5.47 & 3.77 & \\
\hline & $(1.68)$ & $(1.67)$ & (1.09) & \\
\hline \multirow[t]{2}{*}{$D_{-} \Delta q_{i t}$} & $-11.76^{*}$ & $-11.28^{*}$ & $-9.66^{*}$ & $-8.36^{*}$ \\
\hline & $(-3.95)$ & $(-3.63)$ & $(-2.94)$ & $(-2.73)$ \\
\hline \multirow[t]{2}{*}{$P R_{i t}$} & -1.77 & -1.82 & -2.04 & -2.83 \\
\hline & $(-1.09)$ & $(-1.12)$ & $(-1.21)$ & $(-1.74)$ \\
\hline \multirow[t]{2}{*}{$\Delta c w_{i t}$} & & -0.03 & & \\
\hline & & $(-0.54)$ & & \\
\hline \multirow[t]{2}{*}{$I_{-} \Delta c w_{i t}$} & & & $-0.27^{*}$ & $-0.29^{*}$ \\
\hline & & & $(-2.25)$ & $(-2.33)$ \\
\hline \multirow[t]{2}{*}{$D_{-} \Delta c w_{i t}$} & & & 0.27 & $0.29^{*}$ \\
\hline & & & $(1.86)$ & $(1.99)$ \\
\hline Year dummies & Yes & Yes & Yes & Yes \\
\hline Firm fixed effects & Yes & Yes & Yes & Yes \\
\hline Instrumental variables & Yes & Yes & Yes & Yes \\
\hline $\begin{array}{l}\text { Critical prob. of Sargan's } \\
\text { test }\end{array}$ & 0.45 & 0.40 & 0.70 & 0.53 \\
\hline Cragg-Donald statistic & 9.57 & 9.03 & 3.92 & 4.99 \\
\hline $\mathbf{N}$ & 6998 & 6998 & 6998 & 6998 \\
\hline
\end{tabular}

We study in several ways the properties of the instruments used to obtain the results displayed in Table 2 . Firstly, a valid instrument has to be exogeneous. For all models reported in Table 2, the absence of correlation between the residual and the instruments is accepted to at least the $40 \%$ level. Secondly, the 
instruments must not be weak. We document this property using Fisher and Cragg-Donald (1993) statistics. Indeed, Staiger and Stock (1997) suggest as a rule of thumb, in model with a single endogenous variable, to consider instruments as weak when their first stage Fisher statistic does not excess the threshold of 10. Our model comprises multiple endogeneous variables, and this rule does not apply here. We however report in Table A2-2 in Appendix 2, for information, the results of the first stage and the Fisher statistics computed with the number of excluded instruments of the model in the last column of Table 2. An approach dedicated to model with multiple endogeneous variables is described in Stock and Yogo (2002). They propose to test the assumption of weak instruments in comparing the Cragg - Donald statistic with values they tabulate. However, critical values are only tabulated for models with less than two endogeneous variables, where they are respectively of 3.31 and 3.54 for the LIML estimator of a model with 15 excluded instruments (Stock and Yogo, 2002, Table 4, p. 61). Those values are far less than Staiger and Stock (1997) threshold of 10. Our model comprises four endogeneous variables. Cragg Donald statistics of more than 9 for the two first models and of 4.99 for the last one let us think that the instruments are reasonably strong and that the biases are at most small. Results of the third model, where the test statistic is greater than the availables critical values, have to be considered more carefully.

Rises and falls in value added have different effects. Unlike falls, rises have virtually no impact on capital retirement. A $1 \%$ fall in value added is associated with a rise from 8 to 12 precentage points in retirement. The adjustement of production capacities through the retirement thus does seem to occur only in a weak activity setting, companies thus retiring useless overcapacities. This result is not impacted by the inclusion of variables measuring the capital workweek.

The effect of increases and decreases in the workweek of capital are also differenciated. Whereas the magnitude of the coefficients is similar, their significancy is not. A decrease in the workweek of capital does not have a clear significant effect. On the opposite, an increase of $1 \%$ in the capital workweek is related to a decrease in retirement of -0.29 percentage points, showing a complementarity in the increase of production capacity between capital retirement and more intensives capital workweeks.

\subsection{The effect of the structural intensity in capital usage}

Model (3) is now estimated, so as to characterize the impact of the structural intensity of usage on the retirement. In this model, the permanent level of retirement is measured by the firms fixed effects $\hat{\mu}_{\mathrm{i}}$, estimated with the last model of the preceeding Section (Table 2, rightmost column). Those fixed effects are regressed on the proportion of years during which company $i$ organized its' work in successive shifts This variable captures the structural intensity of the equipments usage over the time period, and Figure A1-3 in Appendix 1 displays its' histogram. It thus measures the impact of an intensive and durable use of capital over several years. We also include as control variables industry dummies (5 different industries are considered) and size dummies (4 different sizes, corresponding to the quartiles of the sizes). Results are provided in Table 3 below.

Tableau 3

Estimates of the structural effects

\begin{tabular}{|c|c|c|c|}
\hline \multirow{2}{*}{$\begin{array}{l}\text { Estimator } \\
S W_{i}\end{array}$} & OLS & OLS & OLS \\
\hline & $\begin{array}{c}\mathbf{0 . 0 1}^{*} \\
(1.98)\end{array}$ & $\begin{array}{r}0.00 \\
(1.15)\end{array}$ & $\begin{array}{c}\mathbf{0 . 0 1}^{*} \\
(2.16)\end{array}$ \\
\hline \multicolumn{4}{|l|}{ Industries : } \\
\hline- food & $\begin{array}{r}0.00 \\
(0.22)\end{array}$ & & $\begin{array}{r}0.00 \\
(0.34)\end{array}$ \\
\hline - $\quad$ consommer goods & $\begin{array}{c}\mathbf{0 . 0 2}^{*} \\
(6.44)\end{array}$ & & $\begin{array}{c}\mathbf{0 . 0 2}^{*} \\
(6.47)\end{array}$ \\
\hline - $\quad$ automotive & 0.01 & & 0.01 \\
\hline
\end{tabular}




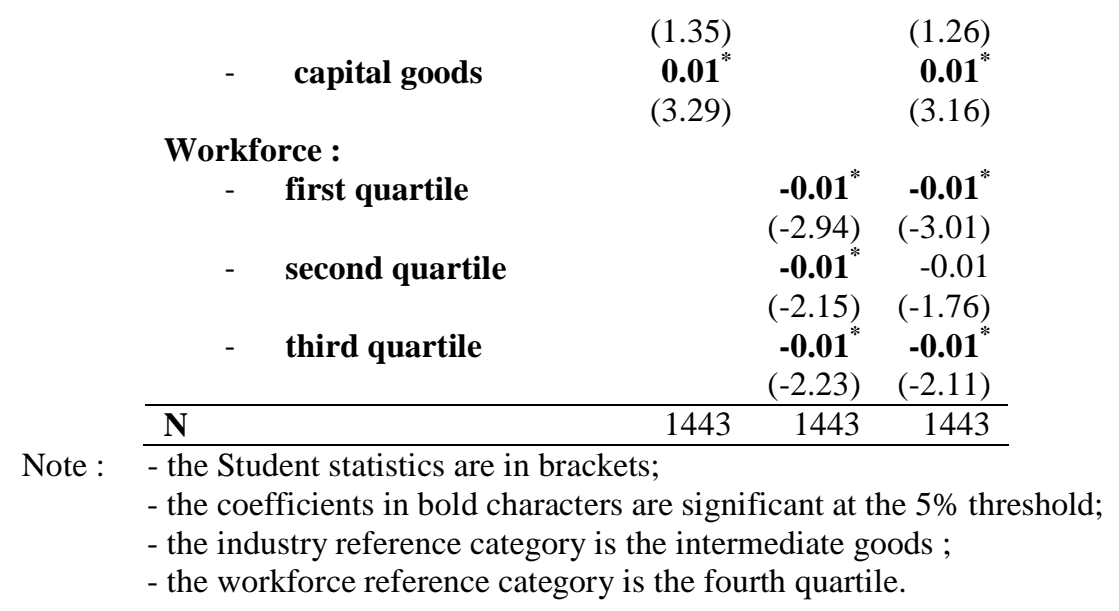

Once the heterogeneity at the industry and size levels is accounted for, the coefficient of the structural intensity variable is positive and significant. The retirement rate is hence increased when some durable pressure is put on the equipement. This result is in line with the intuition of a wear and tear effect. This is however a mechanism of low magnitude. A company managing its' workforce in successive shifts during all the 9 years of the period under study has a $\hat{\mu}_{\mathrm{i}}$ greater of 1 percentage point, and thus its' retirement rate, than a similar firm having never used work in successive shifts. Compared to the influence of the value added, whom a decrease of $1 \%$ induces an increase of 12 percentage points, the impact of the wear and tear effect seems of minor importance.

Contrary to short term variations in the capital workweek, which have a decelerator impact on the capital retirement, long term levels of intensity of use have an accelerator effect. The capital workweek thus has two distinct and opposite effects: cyclically, the capital workweek contributes through the retirement to adjust production capacities, and structurally, the capital retirement is increasing with the intensity of capital usage.

\section{Conclusion}

The empirical analysis of individual company data proposed in this study uses not just the data from the company accounts to calculate the retirement rate, variations in value added and the profitability rate, but also other original data from a survey on the utilisation of production factors. The latter tells us to what extent companies resorted to shift work and to what degree the workweeks of capital varied. The extent to which a company resorts to shift work is used to explain the structural intensity of capital utilisation. Variations in the workweek of capital tell us more about cyclical variations in the intensity of capital utilisation. The sample used for the estimates includes 6,998 observations over the 1996-2008 period. This individual database is, as far as we know, unique for the empirical analysis of the effects of the intensity of capital utilisation on capital retirement. The empirical analysis of capital retirement behaviour is conducted with this data and adjusted for endogeneity biases by means of instrumental variables.

The principal results obtained from the estimation of capital retirement models can be summarised as follows: i) The retirement rate decreases with the variations in cyclical pressures measured by the changes in output and the workweek of capital; this relation corresponds to a countercyclical decelerator effect on capital retirement; ii) The capital retirement rate increases with the structural intensity of capital utilisation; this effect, which corresponds to a wear and tear one, is nevertheless small compared to the decelerator one; iii) The profit rate does not have a significant impact on the 
retirement rate. Compared to previous studies in this field, notably Mairesse and Dormont (1985), the contribution of these results is to show, using original survey data, that the intensity of capital utilisation influences capital retirement in a structurally positive way, via a wear and tear effect, and in a cyclically negative way, via a decelerator effect that completes the already-accounted-for effect of variations in value added.

The approach proposed here is still very partial. A more in-depth representation of capital retirement behaviour would need to be based on a more complete model of the dynamics of capital, analysing the relationship between capital accumulation and capital retirement. Nevertheless, the results obtained appear fairly robust and they comply with basic economic intuition. They suggest that during the current crisis - which notably involved a sharp cyclical contraction of business activity and the intensity of capital utilisation - the retirement of capital must have experienced a marked acceleration. An impact of this nature is not negligible in assessing the potential level of production, and consequently, in determining the position of the economy in the business cycle, for example, using output gap indicators.

\section{$\underline{\text { References }}$}

Angrist, J. and J.-S. Pischke (2009) : Mostly Harmless Econometrics: An Empiricist's Companion, Princeton University Press.

Bitros G., N. Hritonenko and Y. Yatsenko (2007) : «Investment, replacement and scrapping in a vintage capital model with embodied technological change », MRPA Paper, $n^{\circ} 3619$, June.

Blundell, R., and S. Bond. (1998) : "Initial conditions and moment restrictions in dynamic panel data models", Journal of Econometrics, vol. 87, pp. 11-143.

Bond, S. and J. Van Reenen (2007) : "Microeconometric models of investment and employment", The Handbook of Econometrics, vol. 6A., pp. 4417-4498.

Burnside C. and M. Eichenbaum (1996) : «Factor-Hoarding and the Propagation of Business-Cycle Shocks », The American Economic Review, vol. 86, no 5, December, pp. 1154-1174.

Cragg, J. and S. Donald (1993) : « Testing identifiability and specification in instrumental variable models", Econometric Theory, vol. 9, pp. 222-240.

Diewert E. and F. Wykoff (2006) : "Depreciation, Deterioration and Obsolescence when there is Embodied or Disembodied Technical Change", University of British Colombia, Department of Economics, Discussion Paper 06-02.

Eisner R. (1977) : Factor in business investment, General series $n^{\circ} 102$. National Bureau of Economic Research and Ballinger. Cambridge.

Flores-Lagunes, A. (2007) : "Finite sample evidence of IV estimators under weak instruments." Journal of Applied Econometrics, vol. 22, pp. 677-694.

Greenwood J., Z. Hercowitz and G. W. Huffman (1988) : "Investment, Capacity Utilisation, and the Real Business Cycle", The American Economic Review, vol 78, no 3, June, pp. 402-417.

Hahn J., J. Hausman and G. Kuersteiner (2004) : «Estimation with weak instruments : accuracy of higherorder bias and MSE approximations », Econometrics Journal, vol. 7, no 1, pp. 272-306.

Hansen L., J. Heaton and A. Yaron (1996) : "Finite Sample Properties of Some Alternative GMM Estimators". Journal of Business and Economic Statistics, vol. 14, No. 3, pp. 262-280.

Jorgenson D. (1996) : "Empirical Studies of Depreciation”, Economic Enquiry, vol. XXXIV, January, pp. 2442.

Mairesse J. and B. Dormont (1985) : «Labor and Investment Demand at the Firm Level», European Economic Review, vol 28, pp. 201-231.

OCDE (2009) : Measuring Capital - OECD Manual, .

Stock J. and M. Yogo (2002) : «Testing for weak instruments in liner IV regression », NBER Technical Working Paper, $\mathrm{n}^{\circ} 284$.

Veracierto M. (2002) : "Plant-Level Irreversible Investment and Equilibrium Business Cycles", The American Economic Review, vol. 92, n 1, pp. 181-197.

Staiger, D. and J. Stock (1997) : «Instrumental variables regression with weak instruments », Econometrica, 
vol 65, pp. 557-586.

Wooldridge, J. (2001) : Econometric Analysis of Cross Section and Panel Data, MIT Press. 
Appendix 1

Table A1-1

\begin{tabular}{|c|c|c|c|c|c|c|c|c|c|}
\hline Variable & Notation & Source* & $\begin{array}{c}1^{\text {st }} \\
\text { decile }\end{array}$ & $\begin{array}{c}1^{\text {st }} \\
\text { quartile }\end{array}$ & Median & $\begin{array}{c}3^{\text {rd }} \\
\text { quartile }\end{array}$ & $9^{\text {th }}$ decile & Average & $\begin{array}{l}\text { Standard } \\
\text { deviation }\end{array}$ \\
\hline Retirement rate & RR & FiBEn & 0 & 0.0089 & 0.0322 & 0.0643 & 0.1206 & 0.0527 & 0.0747 \\
\hline $\begin{array}{c}\text { Change in real value } \\
\text { added }\end{array}$ & $\Delta \mathrm{Q}$ & FiBEn & -0.0016 & -0.0006 & 0.0002 & 0.0009 & 0.0019 & 0.0001 & 0.0018 \\
\hline Profit rate & PR & FiBEn & 0.0003 & 0.0011 & 0.0022 & 0.0039 & 0.0069 & 0.0033 & 0.0042 \\
\hline $\begin{array}{c}\text { Change in the } \\
\text { workweek of capital }\end{array}$ & $\Delta \mathrm{cw}$ & EUFP & -0.05 & 0 & 0 & 0.01 & 0.1 & 0.0099 & 0.0879 \\
\hline
\end{tabular}

* : FiBen and EUFP are short for Fichier Bancaire des Entreprises and Enquête sur l'Utilisation des Facteurs de Production (Bank Company Accounts Databases and Survey on the Utilisation of Production Factors).

Figure A1-1

Estimate of the probability density of the capital retirement rate.

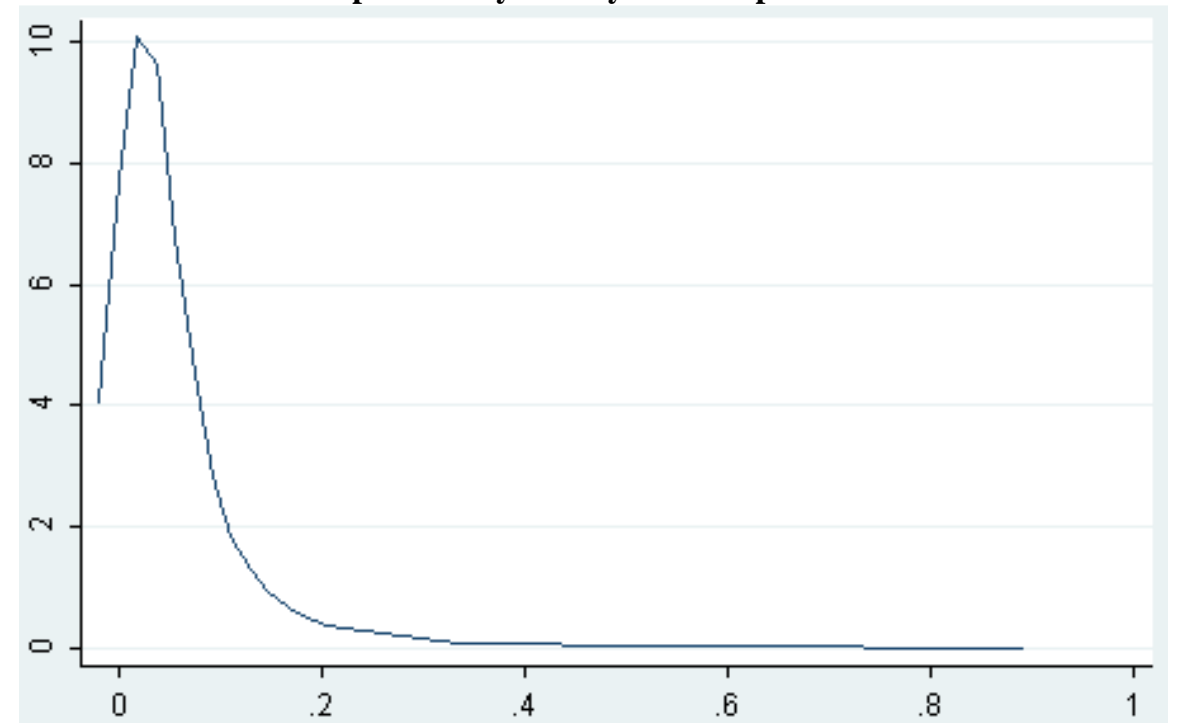

Source: FiBEn database and Survey on the Utilisation of Production Factors. The density is estimated by a kernel method. 
Figure A1-2

Histogram of the variations of the capital workweek over the last 12 months

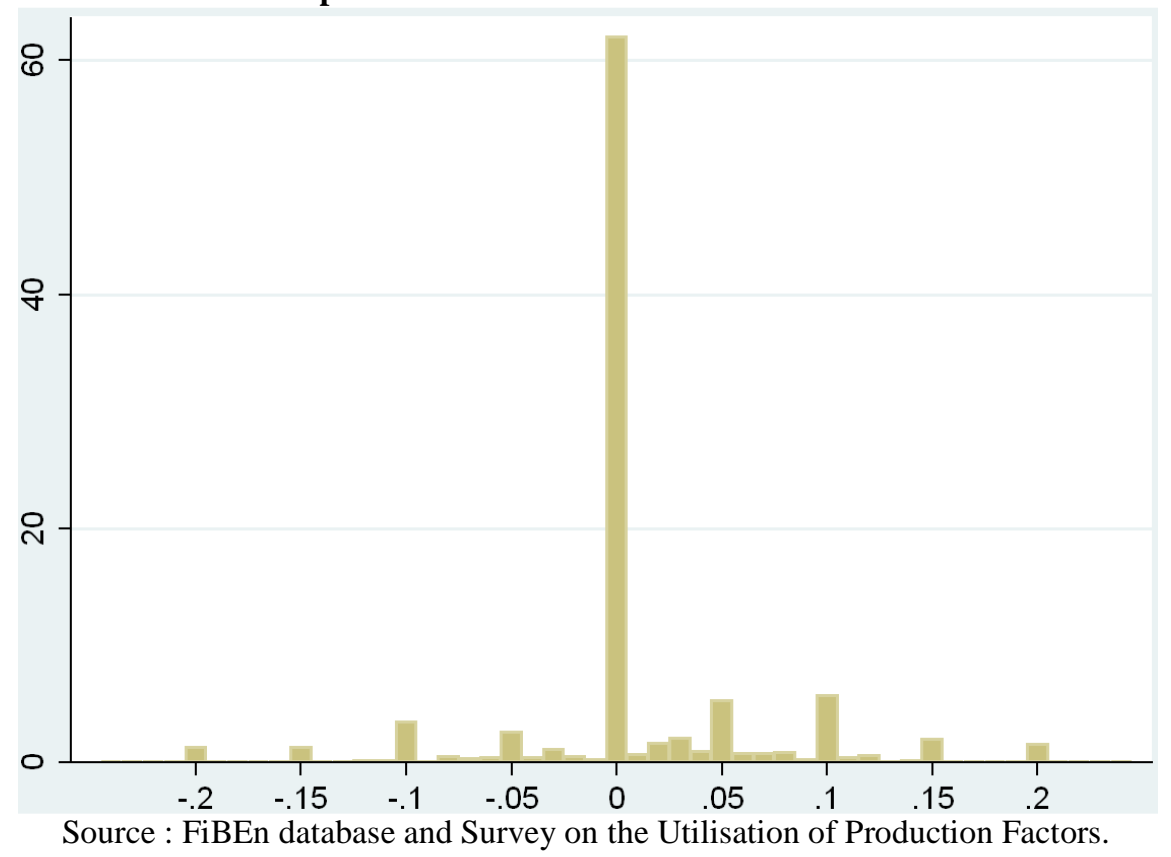

Graphique A1-3

Histogram of the work in successive shifts (in percent of years where the firm is observed)

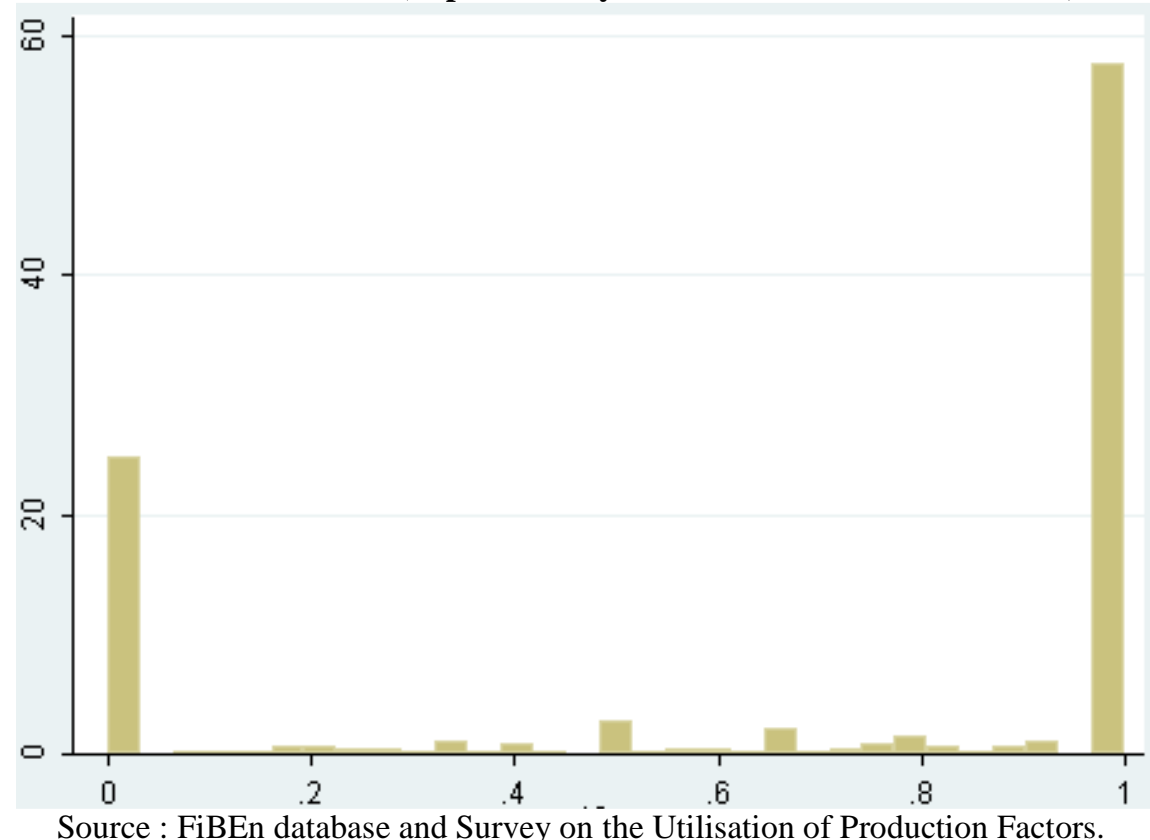


Appendix 2

Results of the first stage regressions

Table 2.1

Results of the first stages of the estimates shown in Table 1

\begin{tabular}{lrr}
\hline Variable & \multicolumn{1}{c}{$\Delta \boldsymbol{q}_{\boldsymbol{i t}}$} & $\boldsymbol{T R E}_{\boldsymbol{i t}}$ \\
\hline$\Delta \boldsymbol{q}_{\boldsymbol{i t}-\mathbf{1}}$ & $-0.32^{*}$ & $0.08^{*}$ \\
& $(-20.51)$ & $(3.89)$ \\
$\Delta \boldsymbol{q}_{\boldsymbol{i t}-\mathbf{2}}$ & $-0.25^{*}$ & $0.08^{*}$ \\
& $(-15.94)$ & $(3.82)$ \\
$\Delta \boldsymbol{q}_{\boldsymbol{i t}-\mathbf{3}}$ & $-0.20^{*}$ & $0.07^{*}$ \\
& $(-13.46)$ & $(3.54)$ \\
$\Delta \boldsymbol{q}_{\boldsymbol{i t}-\mathbf{4}}$ & $-0.16^{*}$ & 0.03 \\
& $(-11.48)$ & $(1.80)$ \\
$\Delta \boldsymbol{q}_{\boldsymbol{i t}-\mathbf{5}}$ & $-0.06^{*}$ & $0.03^{*}$ \\
& $(-5.30)$ & $(1.98)$ \\
$\boldsymbol{T} \boldsymbol{R} \boldsymbol{E} \boldsymbol{N}_{\boldsymbol{i t}-\mathbf{1}}$ & $-0.07^{*}$ & $0.27^{*}$ \\
& $(-6.43)$ & $(19.27)$ \\
\hline $\mathbf{F}$ & 156.22 & 108.25 \\
$\mathbf{N}$ & 6998 & 6998 \\
\hline
\end{tabular}

Note : - The Student $t$ are in brackets;

- Fisher statistics are evaluated with the number of excluded instruments. 
Table 2.2

Results of the first stage regressions of Table 2

\begin{tabular}{|c|c|c|c|c|}
\hline Variable & $D_{-} \Delta q_{i t}$ & $P R_{i t}$ & $I_{-} c w_{i t}$ & $D_{-} c w_{i t}$ \\
\hline \multirow[t]{2}{*}{$D_{-} \Delta q_{i t-1}$} & $-0.30^{*}$ & $0.10^{*}$ & -1.33 & 0.50 \\
\hline & $(-20.42)$ & $(3.23)$ & $(-1.58)$ & $(0.73)$ \\
\hline \multirow{2}{*}{$D_{-} \Delta q_{i t-2}$} & $-0.23^{*}$ & $0.10^{*}$ & $-2.78^{*}$ & -0.64 \\
\hline & $(-14.72)$ & (3.07) & $(-3.22)$ & $(-0.91)$ \\
\hline \multirow[t]{2}{*}{$D_{-} \Delta q_{i t-3}$} & $-0.22^{*}$ & $0.07^{*}$ & $-2.83^{*}$ & -0.46 \\
\hline & $(-14.09)$ & (2.19) & $(-3.26)$ & $(-0.65)$ \\
\hline \multirow[t]{2}{*}{$D_{-} \Delta q_{i t-4}$} & $-0.16^{*}$ & $0.06^{*}$ & $-1.67^{*}$ & -0.13 \\
\hline & $(-12.10)$ & $(2.16)$ & $(-2.19)$ & $(-0.21)$ \\
\hline \multirow[t]{2}{*}{$D \_\Delta q_{i t-5}$} & $-0.12^{*}$ & 0.04 & -0.86 & -0.95 \\
\hline & $(-8.82)$ & (1.32) & $(-1.14)$ & $(-1.55)$ \\
\hline \multirow[t]{2}{*}{$P R_{i t-1}$} & $-0.04^{*}$ & $0.27^{*}$ & -0.44 & -0.45 \\
\hline & $(-6.57)$ & (21.23) & $(-1.25)$ & $(-1.58)$ \\
\hline \multirow[t]{2}{*}{$\overline{\mathbf{c w}}_{\mathrm{jt}}$} & $0.01^{*}$ & 0.01 & $0.40^{*}$ & $0.56^{*}$ \\
\hline & $(4.52)$ & (1.65) & (3.09) & $(5.33)$ \\
\hline \multirow[t]{2}{*}{$I I \_\Delta c w_{i t-1}$} & $0.00^{*}$ & $0.00^{*}$ & $-0.01^{*}$ & $-0.00^{*}$ \\
\hline & (3.83) & $(2.64)$ & $(-2.44)$ & $(-2.00)$ \\
\hline \multirow[t]{2}{*}{$I I \_\Delta c w_{i t-2}$} & 0.00 & 0.00 & $-0.01^{*}$ & -0.00 \\
\hline & $(0.56)$ & $(0.47)$ & $(-4.97)$ & $(-0.71)$ \\
\hline \multirow[t]{2}{*}{$I I \_\Delta c w_{i t-3}$} & 0.00 & 0.00 & $-0.01^{*}$ & -0.00 \\
\hline & (1.92) & (1.21) & $(-4.30)$ & $(-0.47)$ \\
\hline \multirow[t]{2}{*}{$I I \_\Delta c w_{i t-4}$} & -0.00 & -0.00 & $-0.01^{*}$ & $-0.00^{*}$ \\
\hline & $(-0.26)$ & $(-1.64)$ & $(-4.17)$ & $(-2.04)$ \\
\hline \multirow[t]{2}{*}{$I I \_\Delta c w_{i t-5}$} & 0.00 & $0.00^{*}$ & $-0.01^{*}$ & 0.00 \\
\hline & (1.57) & $(2.48)$ & $(-4.65)$ & $(0.50)$ \\
\hline \multirow[t]{2}{*}{$I D \_\Delta c w_{i t-2}$} & -0.00 & -0.00 & 0.00 & $0.01^{*}$ \\
\hline & $(-0.65)$ & $(-1.91)$ & $(0.47)$ & $(5.90)$ \\
\hline \multirow[t]{2}{*}{$I D_{-} \Delta c w_{i t-3}$} & 0.00 & -0.00 & -0.00 & $0.01^{*}$ \\
\hline & (1.15) & $(-1.48)$ & $(-1.79)$ & $(4.76)$ \\
\hline \multirow{2}{*}{$O_{-} c w_{i t}$} & $0.00^{*}$ & 0.00 & 0.01 & 0.01 \\
\hline & (3.64) & $(1.05)$ & $(6.50)$ & $(6.89)$ \\
\hline $\mathbf{F}$ & 61.26 & 44.96 & 11.29 & 10.60 \\
\hline $\mathbf{N}$ & 6998 & 6998 & 6998 & 6998 \\
\hline
\end{tabular}

Note : - The Student $t$ are in brackets ;

- Fisher statistics are evaluated with the number of excluded instruments. 